\title{
In reply to: Presentation of benefits and harms of antidepressants on websites: A cross sectional study
}

Received 18 March 2020

Accepted 28 April 2020

\section{To the Editor,}

In this era where we all turn to the easily assessable Internet for information that is current, the ability to filter out the truth is a labour intensive insurmountable task. This was my conclusion from the insightful report on the content of antidepressant websites for information by Demasi and Gøtzsche [1].

The article focused on the most popular Internet sites for information on antidepressants for Australia, Canada, Denmark, Ireland, New Zealand, Norway, South Africa, Sweden, United Kingdom and United States of America. They included platforms of governmental bodies, advocacy and consumer groups, and were able to identify failure to abide by the principle of bioethics that underpin the practice of medicine. The patient population that needs antidepressants is not only large, but expands to all age groups [2] and certainly is a significant burden on the health care system.

Once COVID-19 was detected in my country, I spent days at home, feeling I had the symptoms. A sore throat and fever for the most part; but alas, my daily temperature checks showed nothing. I just was truly convinced that I was infected with the virus. It is extremely important that we recognise the power of the mind in the state of illness and even more in our ability to be healed. I cannot imagine how utterly confusing it must be for depressed patients to filter through fact from fiction about their medicine with all possible sources of deficient or false information.

With health professionals most likely to benefit from the article, where should they look for the facts to support their oath to patient care? What are the best sources for unbiased information on drug efficacy and safety? It may be useful for the authors of the article to share how the governmental sites matched on their scale of information accuracy. I look forward to more publications on the source of drug information least likely to induce a state of depression.

Maxine Gossell-Williams University of the West Indies

Kingston, Kingston, Jamaica maxine.gossell@uwimona.edu.jm 


\section{References}

[1] Demasi M, Gøtzsche PC. Presentation of benefits and harms of antidepressants on websites: A cross sectional study. International Journal of Risk \& Safety in Medicine. 2020;31(2):53-65. doi:10.3233/JRS-191023.

[2] Charlson F, van Ommeren M, Flaxman A, Cornett J, Whiteford H, Saxena S. New WHO prevalence estimates of mental disorders in conflict settings: A systematic review and meta-analysis. The Lancet. 2019;394(10194):240-8. doi:10.1016/S01406736(19)30934-1. 